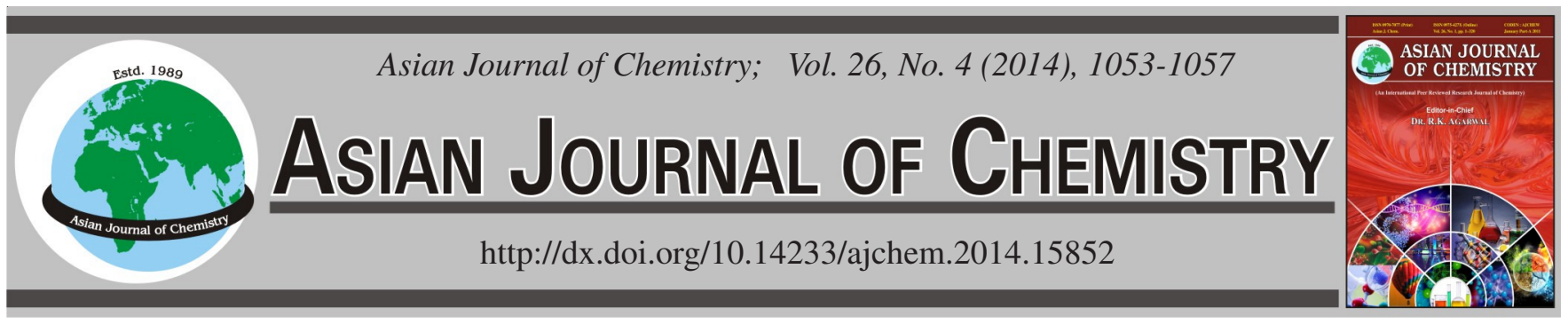

\title{
Inhibition of 1,2-Ethane-bis-(dimethyl benzyl ammonium bromide) for Mild Steel Corrosion in Hydrochloric Acid Solution
}

\author{
C. LAI, X.M. Li*, D.X. Zhang, W.J. YANG and X.G. GuO
}

College of Chemistry and Chemical Engineering, Chongqing University, Chongqing 400044, P.R. China

*Corresponding author: Tel/Fax: +86 23 65105659; E-mail: laichuanemail@163.com; 591896541@qq.com

\begin{abstract}
Inhibition of 1,2-ethane-bis-(dimethyl benzyl ammonium bromide) for mild steel corrosion in $\mathrm{HCl}$ solution were studied by weight loss measurements, potentiodynamic polarization measurements, SEM and AFM techniques. Weight loss measurements indicate that the 1,2ethane-bis-(dimethyl benzyl ammonium bromide) acts as a good inhibitor for mild steel corrosion in $\mathrm{HCl}$ solution. The adsorption of 1,2ethane-bis-(dimethyl benzyl ammonium bromide) on mild steel surface obeys Langmuir adsorption isotherm and the corrosion inhibition depends on chemisorptions. Polarization curves measurements show that the 1,2-ethane-bis-(dimethyl benzyl ammonium bromide) is a mixed-type inhibitor. In this work, the effect of acid concentration and immersion time were also investigated.
\end{abstract}

Keywords: Ammonium, Acid solution, Corrosion inhibitor, Weight loss, Adsorption.

\section{INTRODUCTION}

Nowadays, mild steel is extensively applied, especially in petroleum, chemical and electrochemical industries ${ }^{1-3}$. Corrosion problem of mild steel is then becoming to be the main subject during industrial cleaning, acid pickling or oilwell acidizing ${ }^{4-6}$ and hydrochloric acid and sulfuric acid are the two kinds of acids mostly used ${ }^{7-9}$. Addition of inhibitors is one of the most effective methods for protecting of metallic surfaces against corrosion in acid pickling. Even at a small loading, it still can control, reduce, or prevent reactions between metal and its surroundings ${ }^{10-13}$.

Gemini surfactants have been developed as a new generation of surfactants. This kind of surfactant have two hydrophilic groups and two hydrophobic groups in their structures. At present, gemini surfactants are also used as a novel kind of corrosion inhibitor, the straight chains of alkyls usually take the role of hydrophobic group in many reports ${ }^{14-17}$. There are few studies focusing on the inhibition behavior of the gemini surfactant in which structure the benzyl acts as hydrophobic groups. Thus, in this paper the inhibition of 1,2-ethane-bis(dimethyl benzyl ammonium bromide) for mild steel corrosion in $\mathrm{HCl}$ solution were investigated.

\section{EXPERIMENTAL}

Corrosion inhibitor of 1,2-ethane-bis-(dimethyl benzyl ammonium bromide) was synthesized by $N, N, N^{\prime}, N^{\prime}$-tetramethy-lethylenediamine and benzyl bromide in acetonitrile (Scheme-I).

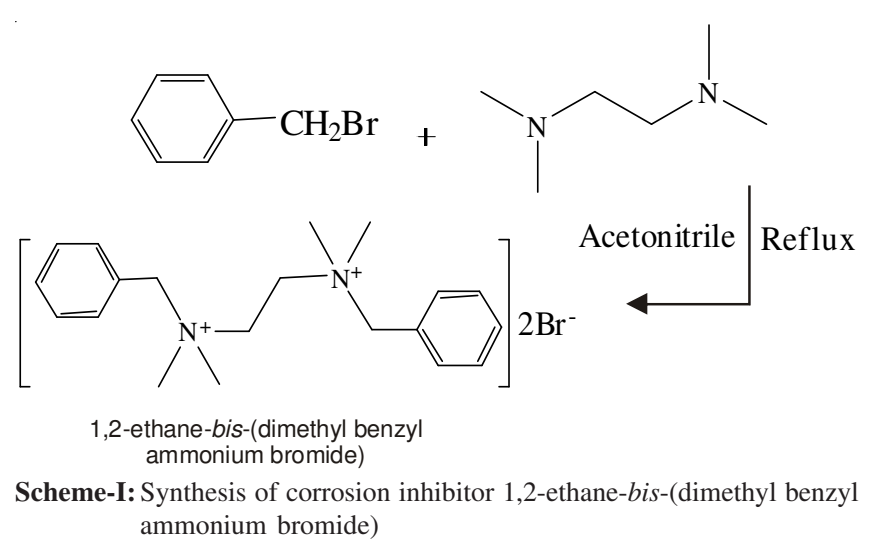

The mild steel specimens used in the weight loss measurements, which were mechanically cut into $0.2 \mathrm{~cm} \times 2.0 \mathrm{~cm} \times$ $4.0 \mathrm{~cm}$ dimensions. The electrode was prepared by embedding the mild steel in epoxy resin and exposing a flat surface of approximately $0.785 \mathrm{~cm}^{2}$ to the electrolyte. All of the tests were performed in $\mathrm{HCl}$ solutions with and without addition of 1,2-ethane-bis-(dimethyl benzyl ammonium bromide). The aggressive acid solution was prepared by dilution of analytical grade $37 \% \mathrm{HCl}\left(1.18 \mathrm{~g} \mathrm{~cm}^{-3}\right)$ with distilled water.

\section{Corrosion test}

Weight loss measurements: Before experiment, the mild steel specimens were mechanically abraded with a series of emery paper (400, 800, 1200 and 1500), followed by cleaning with acetone and distilled water and then stored in the vacuum 
desiccators. Weight loss measurements were carried out by weighing the mild steel specimens before and after immersion in $0.5 \mathrm{M} \mathrm{HCl}$ with and without 1,2-ethane-bis-(dimethyl benzyl ammonium bromide) for $6 \mathrm{~h}$ at $298 \mathrm{~K}$. Duplicate experiments were performed in each case and a mean value of the weight loss was determined. The inhibition efficiency (IE \%) and surface coverage $(\theta)$ were calculated using eqns. (1) and (2), respectively ${ }^{1,4,8}$ :

$$
\begin{aligned}
\mathrm{IE}(\%) & =\frac{\mathrm{W}_{0}-\mathrm{W}_{1}}{\mathrm{~W}_{0}} \times 100 \\
\theta & =\frac{\mathrm{W}_{0}-\mathrm{W}_{1}}{\mathrm{~W}_{0}}
\end{aligned}
$$

where $\mathrm{W}_{0}$ and $\mathrm{W}_{1}$ are values of the weight loss without and with addition of the inhibitor 1,2-ethane-bis-(dimethyl benzyl ammonium bromide).

Potentiodynamic polarization measurements: Potentiodynamic polarization measurements were conducted using the CHI440A electrochemical system (China). A saturated calomel electrode (SCE) and a graphite electrode were used as the reference and the counter electrodes, respectively. All potentials were measured versus SCE. Prior to each measurement, the working electrode was mechanically abraded with a series of emery paper (400, 800, 1200 and 1500), rinsed with distilled water and acetone. Potentiodynamic polarization curves were obtained by changing the electrode potential automatically from $-150 \mathrm{mV}$ to $+150 \mathrm{mV}$ versus open circuit potential (OCP) with the scan rate of $1 \mathrm{mV} \mathrm{s}^{-1}$. The inhibition efficiency (IE \%) were calculated using eqn. (3) $)^{1,4,8}$ :

$$
\operatorname{IE}(\%)=\frac{\mathrm{I}_{0}-\mathrm{I}_{1}}{\mathrm{I}_{0}} \times 100
$$

where $I_{0}$ and $I_{1}$ are values of the corrosion current densities without and with addition of the inhibitor 1,2-ethane-bis(dimethyl benzyl ammonium bromide).

SEM and AFM techniques: The mild steel specimens were mechanically abraded with a series of emery paper (400, 800,1200 and 1500), rinsed with distilled water and acetone. After immersion in $0.5 \mathrm{M} \mathrm{HCl}$ with and without addition of 1,2-ethane-bis-(dimethyl benzyl ammonium bromide) at $298 \mathrm{~K}$ for $2 \mathrm{~h}$, the specimens were cleaned with distilled water, dried with a air blaster and then examined with scanning electron microscopy(SEM, VEGA 3 LMU/LMH) and atomic force microscope (AFM, SPI3800N SPA400) techniques.

\section{RESULTS AND DISCUSSION}

The values of corrosion rates (v) and inhibition efficiency (IE \%) obtained from weight loss measurements for 1,2-ethanebis-(dimethyl benzyl ammonium bromide) at different concentrations in $0.5 \mathrm{M} \mathrm{HCl}$ are listed in Table-1. As can be seen from Table-1, it is found that inhibition efficiency increases with increasing inhibitor concentration, while corrosion rates decreases with 1,2-ethane-bis-(dimethyl benzyl ammonium bromide) concentration. The inhibition of mild steel corrosion can be attributed to the adsorption of 1,2-ethane-bis-(dimethyl benzyl ammonium bromide) at the mild steel and acid solution interface ${ }^{9}$. The 1,2-ethane-bis-(dimethyl benzyl ammonium
TABLE-1

RESULTS OF WEIGHT LOSS MEASUREMENTS FOR MILD STEEL IN $0.5 \mathrm{M} \mathrm{HCl}$ SOUTION AT $298 \mathrm{~K}$ WITH DIFFERENT CONCENTRATIONS OF 1,2-ETHANE-BIS-(DIMETHYL BENZYL AMMONIUM BROMIDE)

\begin{tabular}{ccccc}
\hline $\left.\mathrm{c}(\mathrm{mg} \mathrm{L})^{-1}\right)$ & $\mathrm{V}\left(\mathrm{mg}\left(\mathrm{cm}^{2} \mathrm{~h}\right)^{-1}\right.$ & $\mathrm{IE}(\%)$ & $\theta$ & $\mathrm{c} / \theta$ \\
\hline 0 & 0.4598 & - & - & 0 \\
40.0 & 0.04461 & 90.30 & 0.9030 & 44.30 \\
80.0 & 0.04171 & 90.93 & 0.9093 & 87.98 \\
100 & 0.03719 & 91.91 & 0.9191 & 108.8 \\
120 & 0.03128 & 93.19 & 0.9319 & 128.8 \\
160 & 0.02680 & 94.17 & 0.9417 & 169.9 \\
\hline
\end{tabular}

bromide) acts as a good inhibitor, when the concentration of 1,2-ethane-bis-(dimethyl benzyl ammonium bromide) reached $160 \mathrm{mg} \mathrm{L}^{-1}$ at $298 \mathrm{~K}$ that the inhibition efficiency is up to $94.17 \%$. Good performance of 1,2-ethane-bis-(dimethyl benzyl ammonium bromide) as a corrosion inhibitor may be due to the presence of aromatic rings and nitrogen atoms in their structures $^{9}$.

Adsorption isotherm: The primary step in the action of inhibitor in acid solution is adsorption onto the metal surface, which is usually oxide-free. The adsorbed inhibitor then acts to retard the cathodic and/or anodic electrochemical corrosion reaction. It has been reported that the mechanism of inhibition of an inhibitor may vary with factors such as concentration, $\mathrm{pH}$, nature of the anion of the acid and nature of the metal ${ }^{18}$. Basic information on the interaction between the inhibitor and the mild steel surface can be provided by the adsorption isotherm. In order to obtain the isotherm, attempts were made to fit the $\theta$ values (Table-1) to various isotherms including Langmuir, Temkin, Frumkin and Flory-Huggins isotherm ${ }^{18}$. Langmuir adsorption isotherm is described by the following equation:

$$
\frac{\mathrm{c}}{\theta}=\mathrm{c}+\frac{1}{\mathrm{k}_{0}}
$$

where $\mathrm{c}$ is the concentration of 1,2-ethane-bis-(dimethyl benzyl ammonium bromide), $\mathrm{K}_{0}$ is the equilibrium constant of the adsorption process.

The relationship between c/ $\theta$ (Table-1) and concentration (c) of 1,2-ethane-bis-(dimethyl benzyl ammonium bromide) are shown in Fig. 1. Langmuir adsorption isotherm was found to be the best description $\left(\mathrm{R}^{2}=0.9997\right)$ of the adsorption behavior of 1,2-ethane-bis-(dimethyl benzyl ammonium bromide) among several adsorption isotherms assessed.

The equilibrium constant of adsorption $\left(\mathrm{K}_{0}, \mathrm{~K}_{\mathrm{ads}}\right)$ for adsorption process is related to the free energy of adsorption $\left(\Delta \mathrm{G}_{\text {ads }}^{0}\right)$, which can be expressed by eqns. 5 and 6 :

$$
\begin{gathered}
\mathrm{K}_{\mathrm{ads}}=\frac{1}{55.5} \exp \left(-\frac{\Delta \mathrm{G}_{\mathrm{ads}}^{0}}{\mathrm{RT}}\right) \\
\mathrm{K}_{\mathrm{ads}}=\mathrm{M}_{\mathrm{r}} \times \mathrm{K}_{0} \times 10^{3}
\end{gathered}
$$

where 55.5 is the molar concentration of water in the solution expressed in molarity units $\left(\mathrm{mol} \mathrm{L}^{-1}\right), \mathrm{R}$ is gas constant (8.314 $\mathrm{JK}^{-1} \mathrm{~mol}^{-1}$ ) and $\mathrm{T}$ is absolute temperature $(\mathrm{K})$.

From eqns. (4), (5) and (6), the free energy of adsorption can be calculated, which is $-39.12 \mathrm{KJ} \mathrm{mol}^{-1}$. The result indicates 


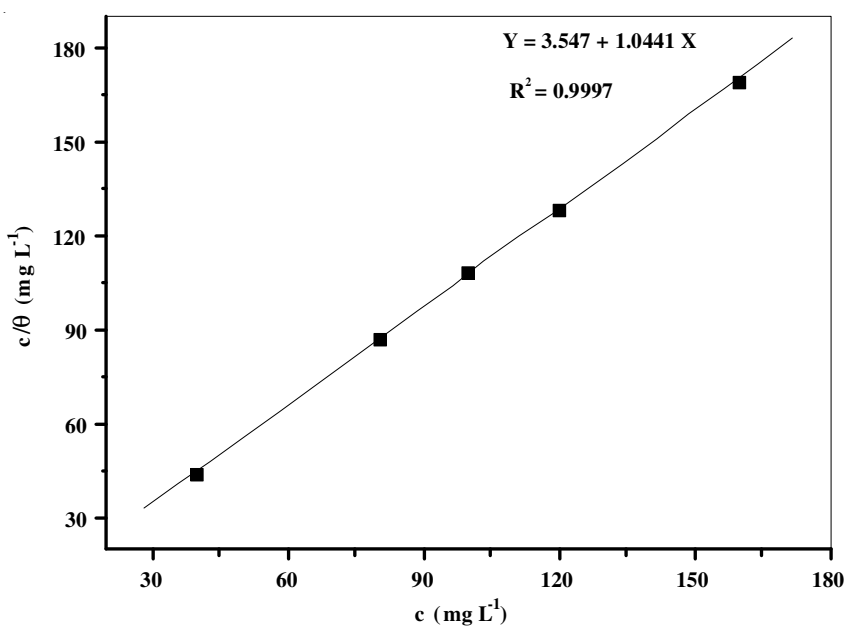

Fig. 1. Langmuir isotherm for adsorption of 1,2-ethane-bis-(dimethyl benzyl ammonium bromide) on mild steel surface in $0.5 \mathrm{M} \mathrm{HCl}$ at $298 \mathrm{~K}$

that the 1,2-ethane-bis-(dimethyl benzyl ammonium bromide) for mild steel in $0.5 \mathrm{M} \mathrm{HCl}$ depends on chemisorption ${ }^{18-20}$. The negative values ensure the spontaneity of the adsorption process and stability of the adsorbed layer on the mild steel surface $^{18}$.

Potentiodynamic polarization results: Both anodic and cathodic polarization curves for mild steel in $0.5 \mathrm{M} \mathrm{HCl}$ solution with different concentrations of 1,2-ethane-bis-(dimethyl benzyl ammonium bromide) are shown in Fig. 2. The electrochemical parameters such as corrosion potential $\left(\mathrm{E}_{\mathrm{corr}}\right)$, cathodic and anodic Tafel slopes ( $\beta \mathrm{c}$ and $\beta \mathrm{a})$ and corrosion current $\left(\mathrm{I}_{\text {corr }}\right)$ obtained from polarization measurements are listed in Table- 2 . These results reveal that after adding 1,2-ethane-bis-(dimethyl benzyl ammonium bromide) the corrosion current density decreases remarkably with the increasing con centration of 1,2-ethane-bis-(dimethyl benzyl ammonium bromide), while the inhibition efficiency increases. The addition of 1,2-ethanebis-(dimethyl benzyl ammonium bromide), both of the cathodic and anodic reactions were obviously suppressed in comparison with those in blank solution. The best inhibition in the short time tests occurred when the 1,2-ethane-bis-(dimethyl benzyl

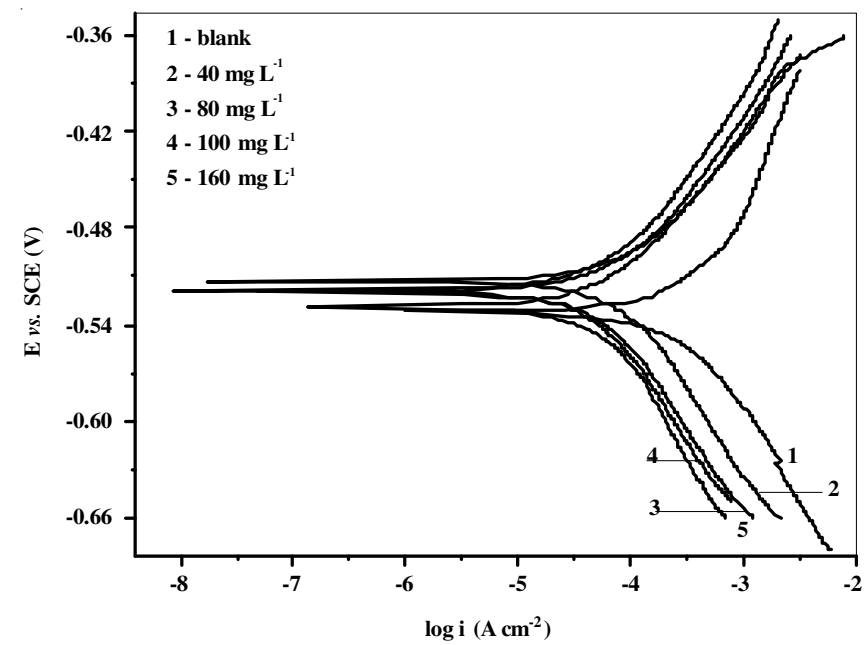

Fig. 2. Potentiodynamic polarization curves for mild steel in $0.5 \mathrm{M} \mathrm{HCl}$ solution with different concentrations of 1,2-ethane-bis-(dimethyl benzyl ammonium bromide) at $298 \mathrm{~K}$

\begin{tabular}{cccccc}
\hline \multicolumn{5}{c}{ TABLE-2 } \\
ELECTROCHEMICAL PARAMETERS AND INHIBITION \\
EFFICIENCIES WITH DIFFERENT CONCENTRATIONS \\
OF 1,2-ETHANE-BIS-(DIMETHYL BENZYL \\
AMMONIUM BROMIDE) \\
\hline$c(\mathrm{mg}$ & $\begin{array}{c}\mathrm{E}_{\text {corr }} \\
\mathrm{I}_{\text {corr }}(\mu \mathrm{A}\end{array}$ & $\beta \mathrm{cc}(\mathrm{mV}$ & $\beta \mathrm{a}(\mathrm{mV}$ & $\mathrm{IE}(\%)$ \\
$\left.\mathrm{L}^{-1}\right)$ & $(\mathrm{mV})$ & $\left.\mathrm{cm}^{-2}\right)$ & $\left.\mathrm{dec}^{-1}\right)$ & - \\
\hline 0 & -532.2 & 574.1 & 130.7 & 152.2 & - \\
40 & -499.1 & 128.8 & 124.4 & 82.22 & 77.56 \\
80 & -519.9 & 89.40 & 112.9 & 81.52 & 84.43 \\
100 & -513.4 & 83.60 & 109.7 & 79.95 & 85.44 \\
160 & -519.0 & 73.20 & 108.7 & 75.70 & 87.25 \\
\hline
\end{tabular}

ammonium bromide) concentration was $160 \mathrm{mg} \mathrm{L}^{-1}$. The corrosion potential did not change obviously before and after adding 1,2-ethane-bis-(dimethyl benzyl ammonium bromide), suggesting that the 1,2-ethane-bis-(dimethyl benzyl ammonium bromide) is a mixed-type inhibitor. The similar results have also been reported elsewhere for other inhibitors ${ }^{5,721,22}$.

Effect of acid concentration: The corrosion of mild steel in different concentrations of $\mathrm{HCl}$ solution with $160 \mathrm{mg} \mathrm{L}^{-1}$ 1,2-ethane-bis-(dimethyl benzyl ammonium bromide) were studied by potentiodynamic polarization measurements. The results are shown in Fig. 3. It is clear that the inhibition efficiency decreases with increasing concentration of $\mathrm{HCl}$. This change in the inhibition efficiency suggested that the 1,2ethane-bis-(dimethyl benzyl ammonium bromide) is suitable for preventing the corrosion of mild steel in low concentration of acid. This is due to the stability of 1,2-ethane-bis-(dimethyl benzyl ammonium bromide) in $\mathrm{HCl}$ solution decreases with increasing concentration of $\mathrm{HCl}$.

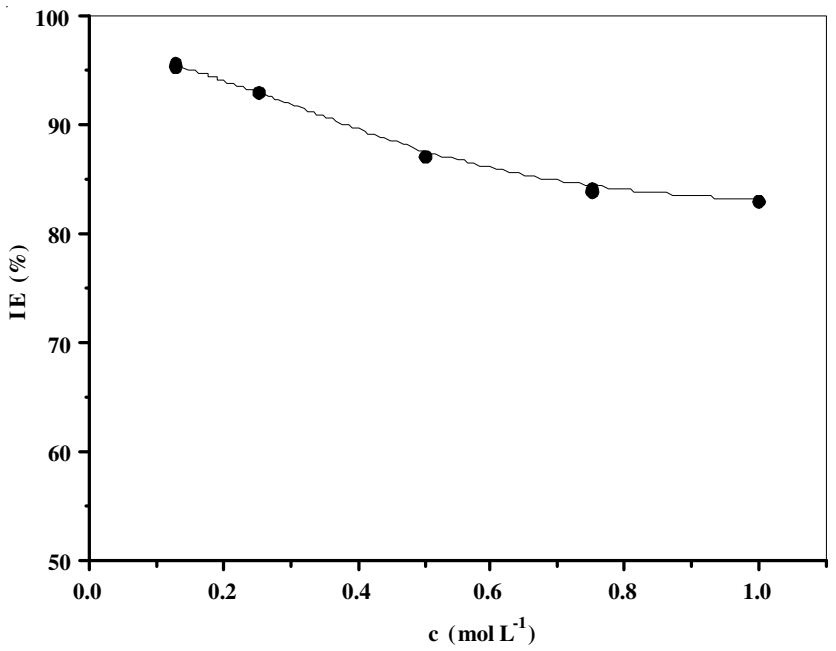

Fig. 3. Relationships between inhibitor efficiency and concentrations of $\mathrm{HCl}$ solution

Effect of immersion time: In order to assess the stability of inhibitive behaviour of 1,2-ethane-bis-(dimethyl benzyl ammonium bromide) on a time scale, potentiodynamic polarization measurements were performed in $0.5 \mathrm{M} \mathrm{HCl}$ with and without $160 \mathrm{mg} \mathrm{L}^{-1}$ 1,2-ethane-bis-(dimethyl benzyl ammonium bromide) at $298 \mathrm{~K}$. Inhibition efficiencies were plotted against immersion time as seen from Fig. 4. It is clear that the inhibition efficiency have a little change with increasing concentration $\mathrm{HCl}$. The result indicates that the 1,2-ethane-bis-(dimethyl benzyl ammonium bromide) shows good stability. 


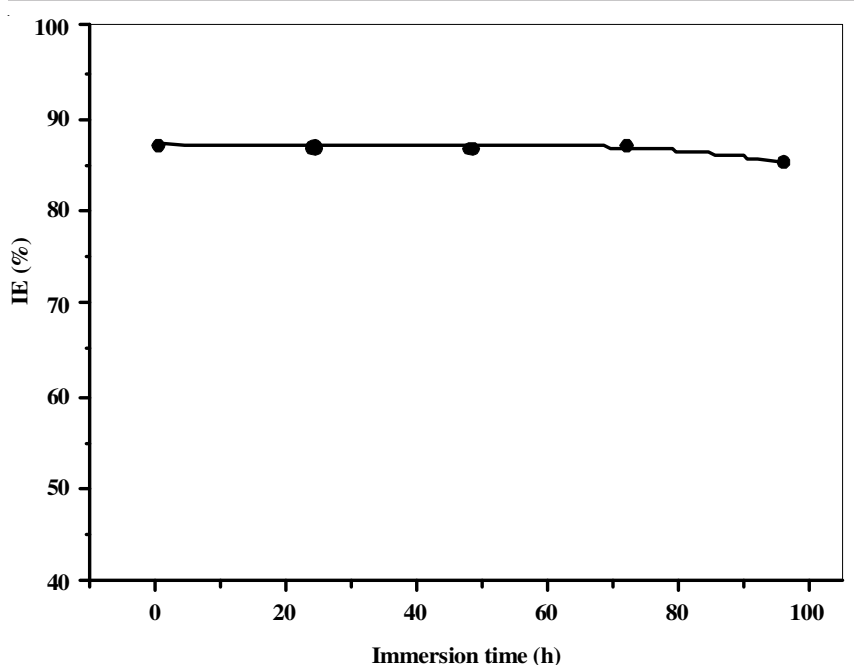

Fig. 4. Relationships between inhibitor efficiency of 1,2-ethane-bis(dimethyl benzyl ammonium bromide) and immersion time

\section{Surface morphological observation}

SEM: The morphologies of mild steel surface immersed in the $0.5 \mathrm{M} \mathrm{HCl}$ for $2 \mathrm{~h}$ in the absence and presence of 1,2ethane-bis-(dimethyl benzyl ammonium bromide) (160 mg $\mathrm{L}^{-1}$ ) were investigated by SEM at $298 \mathrm{~K}$. The results are shown in Figs. 5a,c. It can be observed that the mild steel surface was strongly damaged in the corrosion solution without 1,2-ethanebis-(dimethyl benzyl ammonium bromide) (Fig. 4b), while the mild steel surface exposed to the corrosion solution with
$160 \mathrm{mg} \mathrm{L}^{-1}$ 1,2-ethane-bis-(dimethyl benzyl ammonium bromide), was smooth (Fig. 5c). This could be due to the involvement of the inhibitor molecules in the interaction with the reaction sites of iron surface. This results in an enhancement of surface coverage onto the mild steel surface so that there is a decrease in the contact between iron and the aggressive acid solution and sequentially exhibited excellent inhibition effect.

Atomic force microscopy: In order to further characterize the influence of 1,2-ethane-bis-(dimethyl benzyl ammonium bromide) on the surface morphology of mild steel, the surface morphologies were investigated by AFM technique. The results are depicted in Fig. 6a,c, which all the images showed mountain-like shape. The mild steel surface before immersion seems smooth compared to the mild steel surface after immersion in $0.5 \mathrm{M} \mathrm{HCl}$ without 1,2-ethane-bis-(dimethyl benzyl ammonium bromide) for $2 \mathrm{~h}$. The mean roughness of mild steel surface before immersion(a) and after immersion in $0.5 \mathrm{M} \mathrm{HCl}$ (b) are about 8.473 and $25.46 \mathrm{~nm}$, respectively. It can be observed that the mild steel surface was strongly damaged in the corrosion solution without 1,2-ethane-bis(dimethyl benzyl ammonium bromide) (Fig. 5b). This is due to that the $\mathrm{HCl}$ solution attack on the surface of mild steel. Meanwhile, the roughness decreases to $14.16 \mathrm{~nm}$ (Fig. 5c) for the solution with $160 \mathrm{mg} \mathrm{L}^{-1}$ 1,2-ethane-bis-(dimethyl benzyl ammonium bromide), as a consequence of the protective film formation of an inhibitor adsorption layer. The results are in good agreement with these obtained from the weight loss measurement.
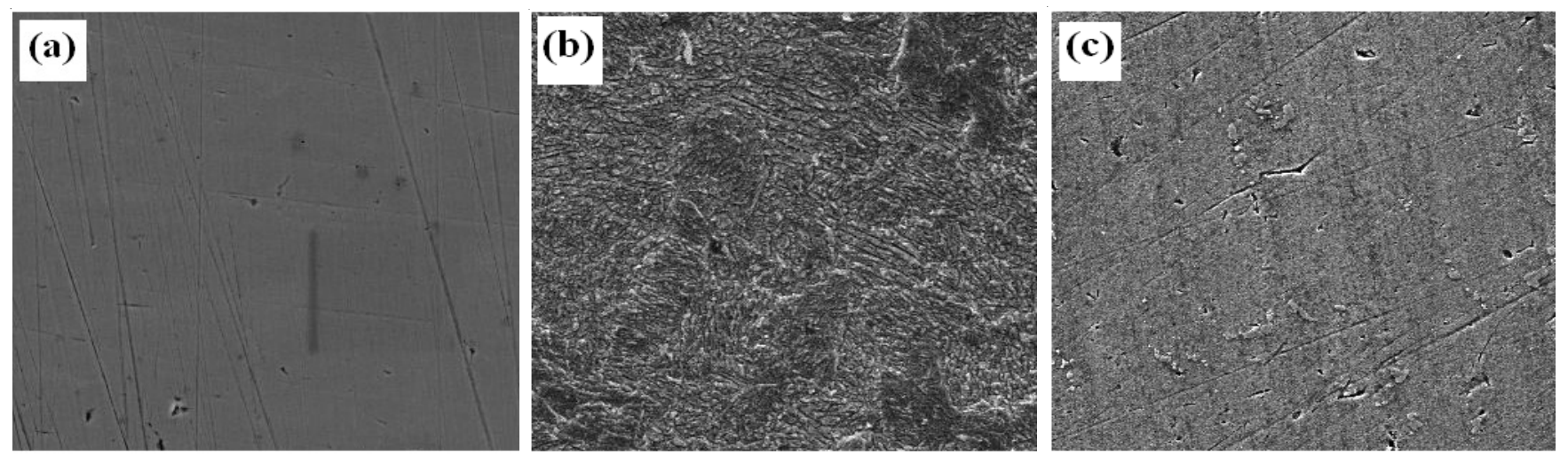

Fig. 5. SEM images for the mild steel surface in $0.5 \mathrm{M} \mathrm{HCl}$ (a) before immersion, (b) $0.5 \mathrm{M} \mathrm{HCl}$ without 1,2-ethane-bis-(dimethyl benzyl ammonium bromide), (c) with $160 \mathrm{mg} \mathrm{L}^{-1}$ of 1,2-ethane-bis-(dimethyl benzyl ammonium bromide)
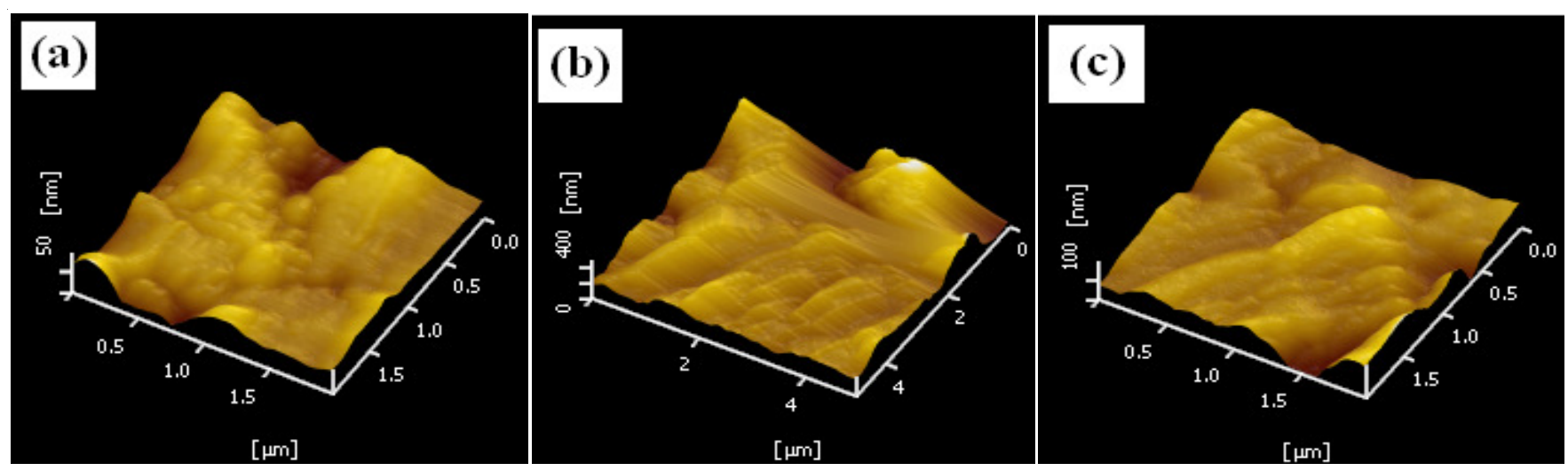

Fig. 6. AFM three-dimensional images for the mild steel surface in $0.5 \mathrm{M} \mathrm{HCl}$ (a) before immersion, (b) $0.5 \mathrm{M} \mathrm{HCl}$ without 1,2-ethane-bis-(dimethyl benzyl ammonium bromide), (c) with $160 \mathrm{mg} \mathrm{L}^{-1}$ of 1,2-ethane-bis-(dimethyl benzyl ammonium bromide) 


\section{Conclusion}

1,2-Ethane-bis-(dimethyl benzyl ammonium bromide) acts as a good inhibitor which is a mixed-type inhibitor for mild steel corrosion in $\mathrm{HCl}$ solution. The results show that the inhibition efficiency increases with increasing concentration of 1,2-ethane-bis-(dimethyl benzyl ammonium bromide), but decreases with increasing acid concentration. When the concentration of 1,2-ethane-bis-(dimethyl benzyl ammonium bromide) reached $160 \mathrm{mg} \mathrm{L}^{-1}$ in $0.5 \mathrm{M} \mathrm{HCl}$ at $298 \mathrm{~K}$ then the inhibition efficiency is up to $94.17 \%$. Meanwhile, The adsorption process of 1,2-ethane-bis-(dimethyl benzyl ammonium bromide) on mild steel surface obeys Langmuir adsorption isotherm and the corrosion inhibition depends on chemisorptions.

\section{ACKNOWLEDGEMENTS}

This work was supported by the National Natural Science Foundation of China (No. 61271059), the Natural Science Foundation Project of Chongqing (No. 2010BB4246), the Science and Technology Development Project of Chongqing (No. CSTC2012gg-yyjs90007).

\section{REFERENCES}

1. R.A. Prabhu, T.V. Venkatesha, A.V. Shanbhag, G.M. Kulkarni and R.G. Kalkhambkar, Corros. Sci., 50, 3356 (2008).
2. I.B. Obot and N.O. Obi-Egbedi, Corros. Sci., 52, 282 (2010).

3. B.I. Ita and O.E. Offiong, Mater. Chem. Phys., 70, 330 (2001).

4. Y.W. Ren, Y. Luo, K.S. Zhang, G.F. Zhu and X.L. Tan, Corros. Sci., 50, 3147 (2008).

5. K. Bhrara, H. Kim and G. Singh, Corros. Sci., 50, 2747 (2008).

6. E.E. Oguzie, Corros. Sci., 50, 2993 (2008).

7. S.S.A. Rehim, O.A. Hazzazi, M.A. Amin and K.F. Khaled, Corros. Sci., 50, 2258 (2008).

8. S.A. Umoren, O. Ogbobe, I.O. Igwe and E.E. Ebenso, Corros. Sci., 50, 1998 (2008).

9. I. Ahamad, R. Prasad and M.A. Quraishi, Corros. Sci., 52, 1472 (2010).

10. X.H. Li, S.D. Deng, G.N. Mu, H. Fu and F.Z. Yang, Corros. Sci., 50, 420 (2008)

11. P. Lowmunkhong, D. Ungthararak and P. Sutthivaiyakit, Corros. Sci., 52, 30 (2010).

12. F.S. de Souza and A. Spinelli, Corros. Sci., 51, 642 (2009).

13. Z.H. Tao, S.T. Zhang, W.H. Li and B.R. Hou, Corros. Sci., 51, 2588 (2009).

14. D. Asefi, M. Arami and N.M. Mahmoodi, Corros. Sci., 52, 794 (2010).

15. L.G. Qiu, A.J. Xie and Y.H. Shen, Appl. Surf. Sci., 246, 1 (2005).

16. L.G. Qiu, Y. Wu, Y.M. Wang and X. Jiang, Corros. Sci., 50, 576 (2008).

17. L.G. Qiu, A.J. Xie and Y.H. Shen, Corros. Sci., 47, 273 (2005).

18. I.B. Obot and N.O. Obi-Egbedi, Corros. Sci., 52, 198 (2010).

19. M. Lebrini, M. Traisnel, M. Lagrenee, B. Mernari and F. Bentiss, Corros. Sci., 50, 473 (2008).

20. M.M. Solomon, S.A. Umoren, I.I. Udosoro and A.P. Udoh, Corros. Sci., 52, 1317 (2010).

21. F. Bentiss, M. Bouanis, B. Mernari, M. Traisnel, H. Vezin and M. Lagrenee, Appl. Surf. Sci., 253, 3696 (2007).

22. P. Lowmunkhong, D. Ungthararak and P. Sutthivaiyakit, Corros. Sci., 52, 30 (2010). 